\title{
Erratum to: Posterior implant removal in patients with thoracolumbar spine fractures: long-term results
}

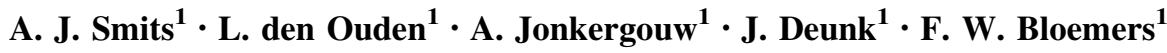

Published online: 27 December 2016

(c) Springer-Verlag Berlin Heidelberg 2016

\section{Erratum to: Eur Spine J}

\section{DOI 10.1007/s00586-016-4883-8}

Unfortunately, the family name of the second author was incorrectly tagged in the xml data. The part of family name "den" was tagged as given name, resulting it is abbreviated as "LD ouden" in Pubmed.

The online version of the original article can be found under doi:10.1007/s00586-016-4883-8.

$\triangle$ A. J. Smits

aj.smits@vumc.nl

1 Department of Traumasurgery, VU University Medical

Centre, De Boelelaan 1117, room 7F020,

1081 HV Amsterdam, The Netherlands 